\title{
Measuring approaches to learning in a problem based learning context
}

\author{
Diana H.J.M. Dolmans', Ineke H.A.P. Wolfhagen', Paul Ginns² \\ ${ }^{1}$ Department of Educational Development and Research, Maastricht University, The Netherlands \\ ${ }^{2}$ Faculty of Education and Social Work, University of Sydney, Australia
}

Correspondence: Diana H.J.M. Dolmans, Department of Educational Development and Research, Maastricht University, The Netherlands, Email: D.Dolmans@educ.unimaas.nl

\begin{abstract}
Objectives: Students in Problem-Based Learning (PBL) are assumed to adopt a deep learning approach and not a surface approach. This study investigated: 1) the reliability and validity of version of the Revised Study Process Questionnaire adapted to the PBL context (PBL-R-SPQ) and 2) the extent to which PBL students use deep or surface approaches, and whether this differs between first and second year students.

Methods: The items of the R-SPQ were reformulated to better fit with a PBL environment, resulting in the PBL-RSPQ. In total 262 students from Maastricht Medical School responded to the PBL-R-SPQ.

Results: A Confirmatory Factor Analysis (CFA) demonstrated that a 9-item Deep Approach scale and a 9-item Surface Approach scale fitted the observed set of data well. Cronbach alphas for the Deep and Surface scales were 0.76 and 0.74 , respectively. First year students reported signifi
\end{abstract}

cantly higher Deep Approach scores $(M=3.60, S D=.48)$ than second year students $(M=3.40, S D=.48)(p=.001, d$ $=.42$ ). Conversely, second year students reported significantly higher Surface Approach scores, $(M=2.45, S D=.48)$ than first year students $(M=2.26, S D=.52)(p=.003, d=$ .38).

Conclusions: The 18-item PBL-R-SPQ provides a valid and reliable tool to measure students' learning approach in PBL. In addition, PBL students tended to adopt a deep approach rather than a surface approach, which is in line with the assumptions behind PBL, although the second year students have a somewhat less deep approach than the first year students.

Keywords: Problem-based learning, constructivist learning, learning approach, active learning, study process questionnaire

\section{Introduction}

In the mid-seventies, different approaches to student learning were identified: a deep approach and a surface approach. Based on intrinsic interest in the topic, students taking a deep approach try to understand ideas and seek meaning and understanding. ${ }^{1}$ Often driven by a fear of failure, students adopting a surface approach are focused on meeting external requirements, such as assessments, particularly through rote learning. ${ }^{2}$ A deep approach is assumed to positively correlate with achievement and a surface approach is assumed to negatively correlate with achievement. $^{3-9}$ Importantly, Student Learning theorists have argued that approaches to learning are at least in part a function of the teaching and learning environment rather than being "pure" individual differences. ${ }^{10-12}$ Good constructive alignment between teaching and learning activities, assessments, and desired learning outcomes is therefore required if desirable approaches are to be promoted and undesired approaches minimised. ${ }^{12}$

One form of curriculum often promoted by Student Learning theorists is Problem Based Learning (PBL). Although PBL looks different at various schools, three characteristics can be considered as essential: 1) problems as a stimulus for learning, 2) teachers as facilitators of the learning process and 3) group work as stimulus for interaction. ${ }^{13}$ Within PBL, students work in small groups to discuss problems under the guidance of a teacher 
Table 1. Confirmatory factor analysis structure for PBL-R-SPQ - completely standardised factor loadings from congeneric measurement models for the total sample

\begin{tabular}{|c|c|c|c|c|}
\hline \multirow{3}{*}{ Item } & \multicolumn{4}{|c|}{ Factor } \\
\hline & \multicolumn{2}{|c|}{ Deep } & \multicolumn{2}{|c|}{ Surface } \\
\hline & Motive & Strategy & Motive & Strategy \\
\hline $\begin{array}{l}\text { 1. Studying a topic gives me at times a feeling of satisfaction and accomplish- } \\
\text { ment }\end{array}$ & 0.61 & & & \\
\hline $\begin{array}{l}\text { 2. I am only satisfied when I have studied a topic so much that I understand it } \\
\text { deeply }\end{array}$ & & 0.48 & & \\
\hline 5. I feel that almost every topic is interesting once I get into it deeply & 0.60 & & & \\
\hline 6. I often spend extra time on new interesting topics & & 0.50 & & \\
\hline $\begin{array}{l}\text { 9. I find studying topics for my study at times as interesting as watching a movie } \\
\text { or reading a novel }\end{array}$ & 0.53 & & & \\
\hline 10. I test myself on important topics until I understand them completely & & 0.58 & & \\
\hline 13. I work hard at my study because I find my study interesting & 0.33 & & & \\
\hline $\begin{array}{l}\text { 14. I spend a lot of my free time to know more about interesting topics dealt with } \\
\text { in my courses }\end{array}$ & & 0.70 & & \\
\hline $\begin{array}{l}\text { 18. I take care that I did study various resources before the discussion in the } \\
\text { groups }\end{array}$ & & 0.43 & & \\
\hline 3. My aim is to pass the test while studying as little as possible & & & 0.53 & \\
\hline $\begin{array}{l}\text { 4. I only study seriously those topics that are mentioned in the course book or } \\
\text { given by the tutor }\end{array}$ & & & & 0.57 \\
\hline $\begin{array}{l}\text { 7. I do not find the block interesting and keep my self-study to the minimum } \\
\text { required for this block }\end{array}$ & & & 0.49 & \\
\hline $\begin{array}{l}11 . \text { I find I can get by in most assessments by memorizing key sections rather } \\
\text { than trying to understand them }\end{array}$ & & & 0.27 & \\
\hline $\begin{array}{l}\text { 12. I generally restrict my self-study to what is specifically set as I think it is } \\
\text { unnecessary to do anything extra }\end{array}$ & & & & 0.64 \\
\hline $\begin{array}{l}\text { 15. I find it not very meaningful to study topics in depth; it confuses and wastes } \\
\text { times, when all you need is superficial knowledge of the topics }\end{array}$ & & & 0.49 & \\
\hline $\begin{array}{l}\text { 16. I believe that tutors shouldn't expect students to spend much time on topics } \\
\text { that will not be examined }\end{array}$ & & & & 0.46 \\
\hline 19. I see no importance in studying topics which are not likely to be examined & & & 0.59 & \\
\hline $\begin{array}{l}\text { 20. The best way to pass examinations is in my opinion to try to remember as } \\
\text { much answers to likely questions }\end{array}$ & & & & 0.26 \\
\hline $\begin{array}{l}\text { 1. Studying a topic gives me at times a feeling of satisfaction and accomplish- } \\
\text { ment }\end{array}$ & 0.61 & & & \\
\hline $\begin{array}{l}\text { 2. I am only satisfied when I have studied a topic so much that I understand it } \\
\text { deeply }\end{array}$ & & 0.48 & & \\
\hline 5. I feel that almost every topic is interesting once I get into it deeply & 0.60 & & & \\
\hline
\end{tabular}

The teacher acts to facilitate the learning process, rather than to provide knowledge. ${ }^{14-15}$ The interaction in the small group around the problems is assumed to stimulate students to adopt a deep learning approach. One of the earliest studies in which students' approaches to learning in PBL were investigated was conducted by Newble and Clarke. ${ }^{16}$ In their study they demonstrated that students who have been taught PBL become increasingly deep and less surface in their orientations. Several studies appeared in the literature investigating students' approaches to learning in PBL. Some studies demonstrated that PBL students tend to adopt a deeper approach rather than a surface approach to learning. ${ }^{17-20}$

Others, like Nijhuis et al., reported that the students from the problem-based environment showed a high degree of surface learning and a low level of deep learning. ${ }^{21}$ Furthermore, some PBL researchers have noted a shift over the course of time in the quality of students' approaches, with students tending to adopt a more surface approach and a less deep approach over the course of the first year of their study. ${ }^{17,19,20}$ In other words, the results so 56 far are not unambiguous that PBL does indeed stimulate students to adopt a deep approach to learning.

Further research is needed to obtain better insight as to whether PBL curricula do indeed stimulate students towards deep learning instead of surface learning, and whether this changes over the years. In this study we investigated tendencies of PBL students to adopt a deep or surface approach to learning, and whether there are differences between year 1 and year 2 students. We used the Revised two-factor Study Process Questionnaire (R-SPQ) of Biggs et al. ${ }^{2}$, a 20-item questionnaire measuring a deep and a surface approach to learning. The 20-item R-SPQ was adapted to the PBL-environment, since some items within the R-SPQ focus on lecturing and classes, and therefore might not be fully appropriate to measure students' approaches to learning in a constructivist learning environment, as was also argued by Gijbels, et.al. ${ }^{22}$ Although the R-SPQ has been tested for its validity and reliability we tested the validity and reliability of this to a PBL environment adapted version (PBL-R-SPQ). In addition, we measured whether students' deep and surface 
approaches to learning differed between year 1 and 2 students within a PBL-curriculum. Thus, the aim of this study was to investigate whether: 1) an adapted version of the R-SPQ, entitled PBL-R-SPQ yields valid and reliable data about a student's deep and surface approach to learning in a PBL curriculum, and 2) PBL students' relative use of deep and surface approaches to learning, and whether this differs between first and second year students.

Table 2. Mean and standard deviation per item for all students $(N=262)$

\begin{tabular}{|c|c|c|}
\hline Item & $\begin{array}{c}\text { Mean } \\
1-5\end{array}$ & SD \\
\hline \multicolumn{3}{|l|}{ Deep learning approach } \\
\hline 1. Studying a topic gives me at times a feeling of satisfaction and accomplishment & 3.86 & 0.72 \\
\hline 2. I am only satisfied when I have studied a topic so much that I understand it deeply & 3.83 & 0.74 \\
\hline 5. I feel that almost every topic is interesting once I get into it deeply & 3.52 & 0.94 \\
\hline 9. I find studying topics for my study at times as interesting as watching a movie or reading a novel & 2.78 & 0.99 \\
\hline 10. I test myself on important topics until I understand them completely & 3.35 & 0.89 \\
\hline 13. I work hard at my study because I find my study interesting & 4.20 & 0.69 \\
\hline 14. I spend a lot of my free time to know more about interesting topics dealt with in my courses & 2.77 & 0.82 \\
\hline 18. I take care that I did study various resources before the discussion in the groups & 3.98 & 0.78 \\
\hline \multicolumn{3}{|l|}{ Surface learning approach } \\
\hline 3. My aim is to pass the test while studying as little as possible & 2.14 & 0.96 \\
\hline 4. I only study seriously those topics that are mentioned in the course book or given by the tutor & 2.82 & 1.00 \\
\hline 7. I do not find the block interesting and keep my self-study to the minimum required for this block & 2.08 & 0.92 \\
\hline $\begin{array}{l}\text { 11. I find I can get by in most assessments by memorizing key sections rather than trying to understand } \\
\text { them }\end{array}$ & 2.01 & 0.96 \\
\hline $\begin{array}{l}\text { 12. I generally restrict my self-study to what is specifically set as I think it is unnecessary to do anything } \\
\text { extra }\end{array}$ & 2.32 & 0.79 \\
\hline $\begin{array}{l}\text { 15. I find it not very meaningful to study topics in depth; it confuses and wastes times, when all you need } \\
\text { is superficial knowledge of the topics }\end{array}$ & 2.10 & 0.91 \\
\hline 16. I believe that tutors shouldn't expect students to spend much time on topics that will not be examined & 2.77 & 0.96 \\
\hline 19. I see no importance in studying topics which are not likely to be examined & 2.66 & 0.81 \\
\hline $\begin{array}{l}\text { 20. The best way to pass examinations is in my opinion to try to remember as much answers to likely } \\
\text { questions }\end{array}$ & 2.17 & 0.93 \\
\hline
\end{tabular}

\section{Methods}

\section{Context}

The study was conducted in the PBL curriculum of the Maastricht Medical School in the Netherlands. Within this problem-based curriculum, years 1 and 2 are divided into several units in which a multidisciplinary theme is covered. About 340 students enter this medical school per year. All units use PBL as the instructional format and are organized around PBL cases. Students meet twice a week to discuss these PBL cases during a two-hour session.

A teacher guides the tutorial group session. Each unit takes six weeks. At the start of each unit, students within the tutorial groups are rearranged and a new teacher is assigned to each group. All teachers involved in this curriculum had a two-day PBL training and a two-day teacher or tutor training before they started as PBL tutors. During each unit, the teacher works together with one group of about 9 or 10 students.

First and second year students were asked to fill out the questionnaire at the end of their first unit.

\section{Participants}

160 first year students and 133 second year students were invited to complete the PBL-R-SPQ. In total 154 first year students and 108 second year students (in total 262 students) filled out the questionnaire, giving a response rate of $96 \%$ in year 1 and $81 \%$ in year 2 , and a total response rate of $89 \%$. The average age of students when entering the programme is about 18 years, and the majority (about 60\%) of students were female.

\section{Instruments}

The revised two-factor Study Process Questionnaire ${ }^{2}$ is a 20-item self-report instrument. This instrument measures two latent variables: a deep approach to learning (10 items) and a surface approach to learning (10 items). The deep approach latent variable was indicated by two observed variables (Deep Motive and Deep Strategy sub-scales), while the surface approach latent variable was indicated by another two observed variables (Surface Motive and Surface Strategy sub-scales). Nine items were reformulated and adapted to a PBL environment, since these items of the 
R-SPQ focus on lecturing and classes instead of blocks, tutors and groups. The items were rated on a 1-5 scale ( $1=$ never or rarely, $2=$ sometimes, $3=$ half of the time, $4=$ frequently and $5=$ always or almost always). The PBL-RSPQ refers to the students' preferred approach to learning and the actual or ongoing approach to learning in a $\mathrm{PBL}$ curriculum. The PBL-R-SPQ measures whether a student's motives and strategies are predominantly deep or surface.

\section{Data Analysis}

Prior to analysis, the dataset was inspected to determine the extent of missing data. Less than $1 \%$ of cells had missing data, and these data points were imputed using the Expectation Maximization Algorithm. This algorithm in LISREL (a statistical program for structural equation modelling) uses an iterative procedure to create a dataset with no missing values whose covariance matrix is as close as possible to the original dataset with missing values. In order to test the construct validity of the PBL-R-SPQ a confirmatory factor analysis was conducted in which it is tested whether the hypothesized two factor model fits with the observed data, because the original SPQ has a clearly hypothesized two-factor structure. The reliability was tested by calculating Cronbach's alpha coefficient. ${ }^{23-24}$ Mean scores per scale were calculated to examine the nature of students' approaches in this cohort. T-tests were conducted to investigate whether first and second year students' scale scores differed significantly $(\mathrm{p}<.01)$.

\section{Ethics}

Although ethical approval was officially not required at the institute in which the study was conducted, the students were given information about the study before they filled out the questionnaire and the anonymity and confidentiality of the students' responses on the questionnaire were safeguarded.

\section{Results}

\section{Confirmatory factor analysis and reliability analysis of the PBL-R-SPQ}

Because the SPQ has a clearly hypothesised factor structure, analyses reported below follow the sequence of analyses used by Biggs et al. ${ }^{2,25}$ This sequence began with tests of congeneric measurement models of the 4 sub-scales (Deep Motive, Deep Strategy, Surface Motive, and Surface Strategy). These analyses were followed by tests of fit of the overall model, in which sub-scales loaded on two higher order factors (Deep and Surface Approach) which were allowed to correlate. LISREL 8.53 was used to conduct these confirmatory factor analyses. Prior to these analyses, we calculated univariate and multivariate normality statistics using PRELIS 2.54. The data exhibited significant multivariate non-normality (multivariate skewness $\mathrm{z}=$ 11.21, $\mathrm{p}<0.001$, multivariate kurtosis $\mathrm{z}=7.44, \mathrm{p}<0.001)$. To take account of this potential violation of a key assumption of structural equation modelling that the data are normally distributed, all analyses used robust maximum likelihood estimation, a method less sensitive to violations of the normality assumption with large models than other estimation methods. ${ }^{26,27}$

Fit indices reported for the various models include the Comparative Fit Index (CFI) and the standardized root mean square residual (SRMR). The CFI compares the proposed model to the independence model, in which all variables are uncorrelated; values greater than 0.90 and 0.95 indicate acceptable and excellent fit respectively. The SRMR is the mean difference, based on standardized residuals, between the predicted and observed variances and covariances in the model; values below 0.05 indicate good fit. ${ }^{28}$ Finally, having tested the dimensionality of each of the sub-scales and scales, internal consistency estimates of reliability (Cronbach's alpha) were calculated using SPSS.

A congeneric measurement model of the five Deep Motive items had a good fit to the data, CFI $=0.97$, SRMR $=$ 0.038 , but inspection of the completely standardised factor loadings revealed item 17 ("I come to most tutorial group sessions with questions in mind that I want answering") had a very low factor loading (0.11) on the Deep Motive latent construct, suggesting this item was not a reliable indicator of the construct. A congeneric measurement model without this item had a better fit to the data, CFI = 0.98, SRMR $=0.029$, and was accepted; Cronbach's alpha $=$ 0.59. A congeneric measurement model of the five Deep Strategy items had a good fit to the data, CFI $=1.00$, SRMR $=0.013$; Cronbach's alpha $=0.67$. A congeneric measurement model of the five Surface Motive items had a moderately acceptable fit to the data, CFI $=0.91$, SRMR $=0.049$; Cronbach's alpha $=0.59$. A congeneric measurement model of the five Surface Strategy items had a marginally acceptable fit to the data, CFI $=0.91$, SRMR $=0.053$, with inspection of the completely standardised factor loadings revealing item 8 ("I learn some things by rote until I know them by heart even if I do not understand them") had a very low factor loading (0.11). A congeneric measurement model without this item had a better fit to the data, CFI = 0.99 , SRMR $=0.028$, and was accepted; Cronbach's alpha $=$ 0.54 .

Based on the results of the above measurement models, sub-scale scores were calculated based on the average response across the 18 items, since item 8 and 17 were removed. Confirmatory factor analysis was used to test the full model, with Deep Motive and Deep Strategy scores loading on a Deep Approach latent variable, and Surface Motive and Surface Strategy scores loading on a Surface Approach latent variable. The hypothesized full model, given in Figure 1, explained the covariances among the four sub-scales well, CFI $=0.97, \mathrm{SRMR}=0.032$. The correlation between the Deep and Surface Approach latent constructs was estimated as -0.60 . For the total 9-item Deep 
Approach scale, Cronbach's alpha $=0.76$, and for the total 9-item Surface Approach scale, Cronbach's alpha $=0.74$. The factor loading of the items of the PBL-R-SPQ are given in Table 1. The average scores per item are given in Table 2.

\section{Approaches to learning in PBL and differences be- tween cohorts}

As noted above, some PBL researchers have noted a shift over the course of time in the quality of students' approaches, with students tending to adopt a more surface approach and a less deep approach over the course of the first year of their study. ${ }^{17,20}$ We explored whether this pattern of results was present in the Maastricht Medical School PBL programme by comparing the Deep and Surface Approach scores of first and second year students. First year students reported higher Deep Approach scores, $M=3.60, S D=.48$, than second year students, $M=3.40$, $S D=.48$, and this difference was statistically significant, $t(260)=3.41, p=.001$, standardised mean difference (Cohen's $d$ ) $=.42$. Conversely, second year students reported higher Surface Approach scores, $M=2.45, S D=.48$, than first year students, $M=2.26, S D=.52$, and this difference was also statistically significant, $t(251)=2.98, p$ $=.003$, Cohen's $d=.38$.

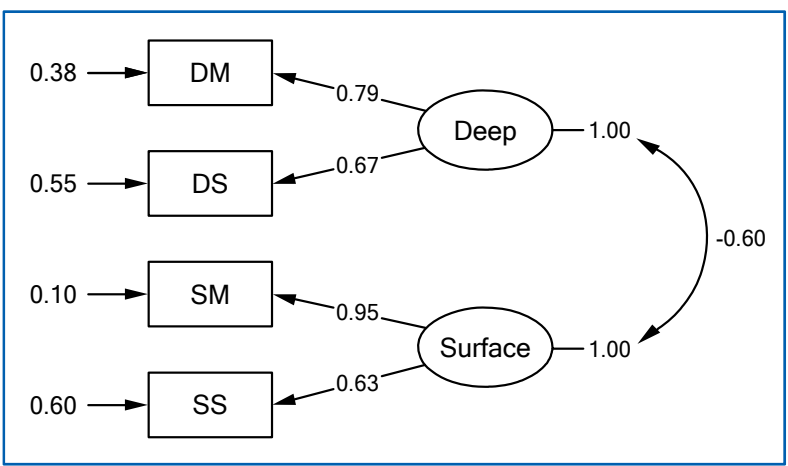

Figure 1. Latent structure of the PBL-R-SPQ (DM=deep motive, $\mathrm{DS}=$ deep strategy, $\mathrm{SM}=$ surface motive, $\mathrm{SS}=$ surface strategy)

\section{Discussion}

The first aim of this study was to test the validity and reliability of the PBL-R-SPQ. The results of the confirmatory factor analysis demonstrated that a 9-item deep approach scale and a 9-item surface approach scale fitted the observed data-set well. The Cronbach alphas of the PBL-RSPQ scales were 0.76 for the deep approach and 0.74 for the surface approach, representing acceptable levels of reliability. In general it can be concluded that the 18 -item PBL-RSPQ provides a valid and reliable tool to measure students' learning approach in a PBL curriculum. Since it only contains 18 items, the instrument can be easily applied to measure PBL students' approaches to learning.

The second aim of this study was to investigate students' relative use of deep and surface approaches to learning in PBL and whether this differs between year 1 and 2 students. The results demonstrated that both the PBL first-year and second-year students tend to adopt a deep approach $(M=3.60$ and $M=3.40$, for year 1 and 2 respectively) rather than a surface approach $(M=2.26$ and $M=$ 2.45 , for year 1 and 2 respectively). This finding is in line with earlier studies in which it was demonstrated that PBL students tend to adopt a deeper approach rather than a surface approach to learning. ${ }^{17-20}$ The results furthermore demonstrated significant differences in scores between first and second year students on the deep and surface approach. Although the scores differed significantly from a statistical point of view, the differences were small from a practical point of view (0.2 points on a scale 1-5). This finding is also in line with previous studies. ${ }^{17,}{ }^{19-20}$ In conclusion, the PBL students seem to use a deep approach rather than a surface approach although the second year students tend to have a somewhat less deep approach and more surface approach than first year students. Perceptions of inappropriate assessment may move students towards a surface approach. ${ }^{5,}{ }^{29}$ Students might have the perception that they need to study less in depth to obtain a sufficient mark on the test in year 2 .

This study has some limitations. First of all, the data reported are self-reports. Since the students were aware of their involvement in a PBL curriculum, it might be possible that they have particular conceptions about learning which might have influenced the results of this study. ${ }^{30}$ Second, the differences between first and second year students should be viewed with some caution given that they are cross-sectional rather than longitudinal in nature: thus, the pattern of results may represent idiosyncrasies related to the particular cohorts.

Further research is needed. First, the PBL-R-SPQ needs to be applied in more PBL settings, to ensure its validity and reliability in more than one setting. Second, longitudinal studies are needed to investigate the development of learning approaches over academic years. Third, it would be interesting to measure not only students' approaches to learning in PBL, but also students' perceptions about the assessment in PBL contexts and whether this influences their learning approach. ${ }^{31}$

\section{References}

1. Trigwell K, Prosser M, Ginns P. Phenomenographic pedagogy and a revised approaches to teaching inventory. Higher Education Research and Development. 2005;24:349-60.

2. Biggs J, Kember D, Leung DYP. The Revised twofactor Study Process Questionnaire: R-SPQ-2F. Brit J Educ Psychol. 2001;71:133-149.

3. Lindblom-Ylänne S, Lonka K. Individual ways of interacting with the learning environment - are they related to study success. Learning and Instruction. 1999;9:1-18.

4. Watkins D. Correlates of approaches to learning: A cross-cultural meta-analysis. In: Sternberg R, Zhang L, 
editors. Perspectives on thinking, learning, and cognitive styles. New Jersey, LEA; 2001.

5. Lizzio A, Wilson K, Simons R. University students' perceptions of the learning environment and academic outcomes: implications for theory and practice. Studies in Higher Education. 2002;27:27-52.

6. Mattick K, Dennis I, Bligh J. Approaches to learning and studying in medical students: validation of a revised inventory and its relation to student characteristics and performance. Med Educ. 2004;38:535-543.

7. Pandey P, Zimitat C. Medical students' learning of anatomy: memorisation, understanding and visualisation. Med Educ. 2007;41:7-14.

8. Reid WA, Duvall E, Evans P. Relationship between assessment results and approaches to learning and studying in year two medical students. Med Educ. 2007;41:754-762.

9. Segers M, Gijbels D, Thurlings M. The relationship between students' perceptions of portfolio assessment practice and their approaches to learning. Educational Studies. 2008;34:35-44.

10. Prosser M, Trigwell K. Understanding learning and teaching: The experience in higher education. Buckingham: Open University Press; 1999.

11. Ramsden P. Learning to teach in higher education. London: Routledge; 2003.

12. Biggs JB, Tang C. Teaching for quality learning at university. Berkshire: Open University Press/McGraw-Hill Education; 2007.

13. Dolmans DHJM, De Grave W, Wolfhagen IHAP, van der Vleuten CPM. Problem-based learning: Future challenges for educational practice and research. Med Educ. 2005;39:732-741.

14. De Grave WS, Dolmans DHJM, van der Vleuten. Profiles of effective tutors in PBL: scaffolding student learning. Med Educ. 1999;33:901-906.

15. Hmelo-Silver CE. Problem-based learning: What and how do students learn? Educ Psychol Rev. 2004;16:235-266. 16. Newble D, Clarke RM. The approaches to learning of students in a traditional and in a problem-based medical school. Med Educ. 1986;20:267-273.

17. Groves M. Problem-based Learning and Learning Approach: Is there a Relationship? Adv Health Sci Educ Theory Pract. 2005;10:315-326.

18. Hofgaard-Lycke K, Grottum P, Stromso HI. Student learning strategies, mental models and learning outcomes in problem-based and traditional curricula in medicine. Med Teach. 2006;28:717-722.
19. Prop A, Muijtjens A, Hommes J. Effect of PBL- innovation on teaching behaviour and students' approaches to learning. Presentation at the AMEE Conference 2006, Genoa, Italy, 14-18 September; 2006.

20. Papinczak T, Young L, Groves M, Haynes M. Effects of a metacognitive intervention on students' approaches to learning and self-efficacy in a first year medical course. Adv Health Sci Educ Theory Pract. 2008;13:213-232.

21. Nijhuis JFH, Segers MSR, Gijselaers WH. Influence of redesigning a learning environment on student perceptions and learning strategies. Learning Environments Research. 2005;8:67-93.

22. Gijbels D, Coertjens L, Vanthournout G, Struyf E, Petegem van P. Changing students' approaches to learning: a two-year study within a university teacher training course. Educational Studies. 2009;35:503-513.

23. Cronbach LJ. Coefficient alpha and the internal structure of tests. Psychometrika. 1951;16:297-334.

24. Schmitt N. Uses and abuses of coefficient alpha. Psychological Assessment.1996;8:350-353.

25. Leung D, Ginns P, Kember D. Examining the cultural specificity of approaches to learning in universities in Hong Kong and Sydney. Journal of Cross-Cultural Psychology. 2008;39:251-266.

26. Raykov T, Marcoulides GA. A first course in structural equation modelling. NJ Mahwah, Lawrence Erlbaum Associates; 2000.

27. Boomsma A, Hoogland JJ. The robustness of LISREL modelling revisited. In: Cudeck R, Toit du S, Sörbom D, editors. Structural equation modelling: Present and future. Lincolnwood IL, Scientific Software International; 2001.

28. Spector PE. Research methods in Industrial and Organizational Psychology: Data collection and data analysis with special consideration to international issues. In: Anderson $\mathrm{N}$, Ones DS, Sinangil HK, Viswesvaran $\mathrm{CH}$, editors. Handbook of Industrial, Work \& Organizational Psychology. London: Sage; 2002.

29. Mattick K, Knight L. High-quality learning: harder to achieve than we think. Med Educ. 2007;41:638-644.

30. Loyens SMM, Rikers RMJP, Schmidt HG. Students' conceptions of constructivist learning: A comparison between a traditional and a problem-based learning curriculum. Health Sci Educ Theory Pract. 2006;11:365-379.

31. Gijbels D, Segers M, Struyf E. Constructivist learning environments and the (im)possibility to change students' perceptions of assessment demands and approaches to learning. Instructional Science. 2008;36:431-443. 